\title{
Exosomes, an Unmasked Culprit in Neurodegenerative Diseases
}

\author{
Federico N. Soria ${ }^{1,2}$, Olatz Pampliega ${ }^{1,2}$, Mathieu Bourdenx ${ }^{1,2}$, Wassilios G. Meissner ${ }^{1,2}$, \\ Erwan Bezard ${ }^{1,2}$ and Benjamin Dehay ${ }^{1,2 *}$
}

${ }^{1}$ Institut des Maladies Neurodégénératives, UMR 5293, Université de Bordeaux, Bordeaux, France, ${ }^{2}$ Centre National de la Recherche Scientifique (CNRS), Institut des Maladies Neurodégénératives, UMR 5293, Bordeaux, France

OPEN ACCESS

Edited by:

Diana K. Sarko,

Southern Illinois University

Carbondale, USA

Reviewed by:

Efthimios M. C. Skoulakis, Biomedical Sciences Research Centre "Alexander Fleming", Greece Andrew Francis Hill,

La Trobe University, Australia

*Correspondence:

Benjamin Dehay

benjamin.dehay@u-bordeaux.fr

Specialty section:

This article was submitted to

Neurodegeneration,

a section of the journal

Frontiers in Neuroscience

Received: 30 November 2016 Accepted: 16 January 2017

Published: 31 January 2017

Citation:

Soria FN, Pampliega O, Bourdenx M, Meissner WG, Bezard E and Dehay $B$

(2017) Exosomes, an Unmasked

Culprit in Neurodegenerative

Diseases. Front. Neurosci. 11:26.

doi: 10.3389/fnins.2017.00026
Exosomes are extracellular nanovesicles $(30-100 \mathrm{~nm})$ generated from endosomal membranes and known to be released by all cell lineages of the Central Nervous System (CNS). They constitute important vesicles for the secretion and transport of multilevel information, including signaling, toxic, and regulatory molecules. Initially thought to have a function merely in waste disposal, the involvement of exosomes in neuronal development, maintenance, and regeneration through its paracrine and endocrine signaling functions has drawn particular attention in recent years. These vesicles, being involved in the clearance and cell-to-cell spreading of toxic molecules, have been naturally implicated in aging, and in several neurodegenerative diseases associated with pathological conversion of proteins, as well as in the transport of other disease-associated molecules, such as nucleic acids or pro-inflammatory cytokines. Our understanding of such unique form of communication may provide not only answers about (patho)physiological processes in the brain, but can also offer means to exploit these vesicles as vehicles for the delivery of biologically relevant molecules or as tools to monitor brain diseases in a non-invasive way. A promising field in expansion, the study of exosomes and related extracellular vesicles has just commenced to unveil their potential as therapeutic tools for brain disorders as well as biomarkers of disease state.

Keywords: exosomes, extracellular vesicles, neurodegeneration, cell-to-cell transmission, biomarkers

\section{INTRODUCTION}

Among intracellular organelles, eukaryotic cells also contain organelles that are released into the microenvironment. These membranous extracellular vesicles can be classified according to their size into exosomes, ectosomes, and apoptotic blebs (Mathivanan et al., 2010), many of which exhibit pleiotropic biological functions. In particular, exosomes were initially thought to act as cellular waste disposal compartments because of their extrusion from the cell, but it was only recently discovered that exosomes contain not only cellular proteins but also act as natural carriers of nucleic acid material in the form of DNA, mRNA transcripts, miRNA, and noncoding RNA (Schorey and Bhatnagar, 2008). They are released under normal as well as pathological conditions and since, have been recognized as a critical messenger for short and long-distance cell-to-cell communication. As such, cells use exosomes in the central nervous system (CNS) as a major route of secretion in order to get rid of waste membranes, harmful RNA or proteins or, more importantly, to act as messengers, and signal carriers to other neural cells, modifying their function in normal physiology as well as in states of disease (Zappulli et al., 2016). In this regard, given their ability to mediate intercellular communication, exosomes are increasingly being considered as one of the actors in 
transporting pathological misfolded proteins that are involved in neurodegenerative diseases and in disseminating disease into and within the brain. Nevertheless, since exosomes would be capable of transporting drugs across the blood brain barrier, their therapeutic potential has generated great interest in the field.

\section{EXOSOMES AND INTERCELLULAR COMMUNICATION}

Studies in a variety of model systems have provided insights about origin, composition, and functions of exosomes. The physiological role of these vesicles is to transport biomolecules between different cells, being considered as a mechanism of paracrine (and possibly endocrine) communication. However, most of the experimental investigations are related to pathophysiological conditions and disease models, from which the physiological function has been inferred. Therefore, it has been assumed that the function of exosomes is maintained during physiological and pathological conditions, although further basic studies about their role would be key to corroborate this assumption.

\section{Exosome Biogenesis}

Three main types of vesicles have been described so far: exosomes, ectosomes and apoptotic blebs. Exosomes range from 30 to $100 \mathrm{~nm}$ in diameter, whereas ectosomes range between 50 and $1000 \mathrm{~nm}$ and apoptotic blebs, released by dying cells, between 50 and $5000 \mathrm{~nm}$. Among them, the best characterized ones are exosomes. Exosomes are membrane-bound spherical nanovesicles of endocytic origin that are released by almost all cell types, and which can be found in abundance in body fluids (Simpson et al., 2008). The biogenesis of exosomes begins with the invagination of endosomal membranes to form multivesicular bodies (MVBs) containing intraluminal vesicles (ILVs) that range from 30 to $100 \mathrm{~nm}$ in diameter (Simons and Raposo, 2009). MVBs can either fuse with lysosomes for cargo degradation, or with the plasma membrane, which leads to the release of the ILVs to the extracellular space as exosomes (Mathivanan et al., 2010).

\section{Exosome Membrane Markers}

General markers for exosome include enrichment in CD9, CD63, CD81, and Heat Shock Cognate 70 (HSC70) proteins, as well as the embryonic stem cell marker Nanog (Sheller et al., 2016). As described in this study, a combination of different methods is used to accurately characterize the exosomes; electron microscopy for shape and morphology, particle sizing, western blot and flow cytometry for detection of specific markers and cargo contents, and UV absorbance for DNA quantification. Altogether, a high-quality isolation method for exosomes, followed by their characterization and identification, is mandatory to distinguish exosomes from other microvesicles.

\section{Exosome Cargo Markers}

The characterization of exosomal cargo will vary depending on the cell type that releases the exosome, and although the diversity in the cargo profile suggests different mechanisms of selection, there is still no study about the molecular details nor whether it is a random event. The myriad of results obtained from the studies that focus on the characterization of exosome content are gathered in different databases such as Exocarta, EVpedia, or Vesiclepedia (Mathivanan and Simpson, 2009; Kalra et al., 2012; Mathivanan et al., 2012; Simpson et al., 2012; Kim et al., 2013). They provide information about the protein, lipid or acid nucleic content of the different types of exosomes. Despite the variety in isolation techniques and different cell types used in these studies, it seems that a significant number of the proteins found in exosomes come from the biogenesis process, as it happens for components of the endosomal sorting complex for transport (ESCRT) pathway, Rab proteins needed for the formation and release of vesicles (Rab27A, Rab11B, ARF6), or the tetraspanins CD9, CD63, and CD81.

Cargo loading into the exosomes can be achieved by different mechanisms, although protein binding to the plasma membrane and its subsequent oligomerization seems to be the main process for cargo acquisition. However, any protein that binds to an exosome cargo could potentially be loaded into the nascent exosomes, as it is the case for RNAs, which typically exist in complex with proteins. Therefore, the selective trafficking of these macromolecules is linked to the delivery of their binding partners. Alternatively, cargo proteins can be covalently linked to exosomes (Yang and Gould, 2013).

Lipids are also loaded into exosomes as cargoes, in which case they share many characteristics with the lipid membranes of their cells of origin. Their main differential characteristic is the enrichment in phosphatidylserine in the outer face of the exosomal membrane, which facilitates the internalization by recipient cells (Subra et al., 2007; Fitzner et al., 2011).

Regarding nucleic acids, exosomes are enriched in small RNAs as compared with DNA, although almost any type of RNA has been found in these vesicles (Abels and Breakefield, 2016). However, the profile of the RNA content in exosomes differs substantially from that of the total cell (Guduric-Fuchs et al., 2012; Jenjaroenpun et al., 2013; Yagi et al., 2016). Similarly, the analysis of different secretomes led to the conclusion that exosomes derived from mesenchymal stromal cells (MSCs) in the bone marrow enhance neurite growth, as opposed to microvesicles or total secretome. The differential profiles in exosomal cargo content found in this study suggest that selective mechanisms underlie the processes of cargo selection and/or reception, which are still unexplored, and could open the door to the development of new therapeutic tools (Lopez-Verrilli et al., 2016).

\section{Exosome Release and Transmission}

Although poorly investigated, exosome release is thought to be affected by other cellular events, and it has been described that synaptic glutamatergic AMPA and NMDA receptors modulate exosome release in differentiated neurons (Lachenal et al., 2011). Indeed, neuronal depolarization and calcium influx events into the neuron after ionomycin treatment enhanced exosome release (Lachenal et al., 2011), suggesting that this is an event that can be modulated and therefore suitable to be developed as a therapeutic tool. Several other works have confirmed the role of exosomes 
in modulating synaptic activity, as for example the polarized delivery of exosomes at synapses (Mittelbrunn et al., 2015). Also, endocannabinoids, which are secreted through extracellular vesicles produced by microglia, are able to inhibit presynaptic transmission (Gabrielli et al., 2015). Exosomes can indeed act as novel mechanisms of trans-synaptic communication, in which synaptogenic factors such as the presynaptic protein Evi are released into the synaptic cleft via these vesicles (Korkut et al., 2009).

Another rising issue in exosome research is that most of the studies use scenarios where a certain biomolecule is overexpressed, due to technical requirements or to the specific pathology that is being studied. It has to be pointed out that overexpression techniques can lead to a forced transmission event that otherwise would not occur in physiological conditions. This concern, together with the fact that exosome release is seldom the primary route of cell-to-cell transmission, question whether exosomes are a complementary but not necessary mechanism of paracrine/endocrine communication.

Once delivered, exosomes are taken up by the recipient cell, in a process that involves fusion with the plasma membrane, and different mechanisms of endocytosis that depend on the cell type (Abels and Breakefield, 2016). For example, in the CNS, neurons internalize exosomes through clathrin-dependent endocytosis or phagocytosis (Feng et al., 2010; Fruhbeis et al., 2013), while microglia internalizes these membrane vesicles through macropinocytosis (Fitzner et al., 2011). The uptake may depend on the cellular state of the recipient cell, since surface ligands recognize receptors on the exosome. However, an important question that remains unanswered about extracellular vesicles is whether the recipient cell has any role in the selection of the receiving cargo, or if this only depends on the emissary cell. Other factors that modulate the uptake of exosomes is the presence of heparin sulfate proteoglycans (HSPGs) on the plasma membrane (Atai et al., 2013; Christianson et al., 2013), or the blockage of specific receptors on the plasma membrane, as it was described for SR-B1 receptor (Plebanek et al., 2015).

\section{EXOSOMES IN NEURODEGENERATIVE DISEASES}

Intercellular communication is a cornerstone in the research of neurodegenerative diseases. Beyond the complex molecular events that take place within the cell, the effects that these can have on neighboring or distant cells are a matter of intense investigation. This is mostly because communication often happens through the extracellular space, the compartment where it is easier to intervene, either by using a therapeutic tool to modify the disease, or by probing and sampling to diagnose or assess disease progression. During the last decade, among the several mechanisms for cell communication studied in neurodegenerative diseases, exosomes and extracellular vesicles have emerged as common players. Clearance and disposal of byproducts or toxic molecules, as well as cell-to-cell transmission of nucleic acids, cytokines and enzymes, but also aggregated or misfolded proteins, are among the several cargos being studied in brain pathophysiology (Figure 1). At this time, most of the advances have been achieved in vitro, but the results are vastly interesting, particularly for the prion-like spreading hypothesis applied in the understanding of neurodegenerative diseases.

\section{Prion Diseases}

Prions are infectious agents consisting of proteins misfolded into aberrant conformations that can transmit their misfolded state to "naïve" proteins of the same type and aggregate with themselves into oligomers and fibrils. According to the prion hypothesis (Prusiner, 1982), these infectious particles operate, thus, as proteopathic seeds that trigger a chain-reaction of refolding and self-aggregation, spreading the pathophysiological status to other cells, and ultimately causing neurodegeneration and loss of gray matter. Transmissible spongiform encephalopathies such as Creutzfeldt-Jacob disease in humans or scrapie in animals, are known to originate from this mechanism (Collinge, 2001). Similarly, in other neurodegenerative diseases such as Alzheimer's or Parkinson's Disease there is also a progressive accumulation of misfolded proteins such as $\beta$-amyloid, tau, and $\alpha$-syn, among others, which occurs concomitantly with the spreading of the pathology between neuroanatomically connected regions. These characteristics have led to the hypothesis that these and other proteinopathies share a common originating mechanism, which has given rise to the "prion-like" hypothesis (Jucker and Walker, 2013).

The idea of exosome-mediated propagation in prion diseases was introduced in the last decade, when Fevrier et al. (2004) found that the prion protein (PrP)-expressing cells could release $\mathrm{PrP}^{\mathrm{C}}$ (normal) and $\mathrm{PrP}^{\mathrm{Sc}}$ (abnormal) in association with exosomes. The first report that linked in vivo the prion disease pathogenesis and exosomes came 4 years later, when Vella et al. (2008) found $\mathrm{PrP}^{\mathrm{C}}$ associated to extracellular vesicles in the CSF of sheep. The interplay between prions and exosomes has just begun to be unveiled in recent years: The biogenesis of exosomes appears to be implicated both in the conversion of $\mathrm{PrP}^{\mathrm{Sc}}$ (Yim et al., 2015) as well as in its packaging (Vella et al., 2007). Moreover, $\mathrm{PrP}^{\mathrm{Sc}}$ can apparently alter the structure (Coleman et al., 2012) and cargo (Bellingham et al., 2012b) of exosomes, and upregulating the exosomal secretion pathway increase the infectiousness of $\operatorname{PrP}^{\mathrm{Sc}}$ (Guo et al., 2016).

\section{Alzheimer's Disease: $\beta$-Amyloid and Tau}

Rajendran et al. (2006) first described in vitro the intracellular $\beta$-cleavage of the amyloid precursor protein (APP) in early endosomes, and the subsequent secretion of $\beta$-amyloid $(A \beta)$ to the extracellular space via exosomes, suggesting a role of these vesicles in $\mathrm{A} \beta$ propagation. There have been no further reports associating exosomal secretion to A $\beta$ spreading, but APP-Cterminal fragments have been found, indeed, in exosomes in vitro (Sharples et al., 2008) and in vivo (Perez-Gonzalez et al., 2012), which at least suggests a role of the exosomal secretory pathway in the generation of $A \beta$. Nonetheless, consensus within the field seems to be that direct cell-to-cell transmission is more prevalent than exosome-mediated transfer for the pathological spreading of A $\beta$ (Bellingham et al., 2012b). 


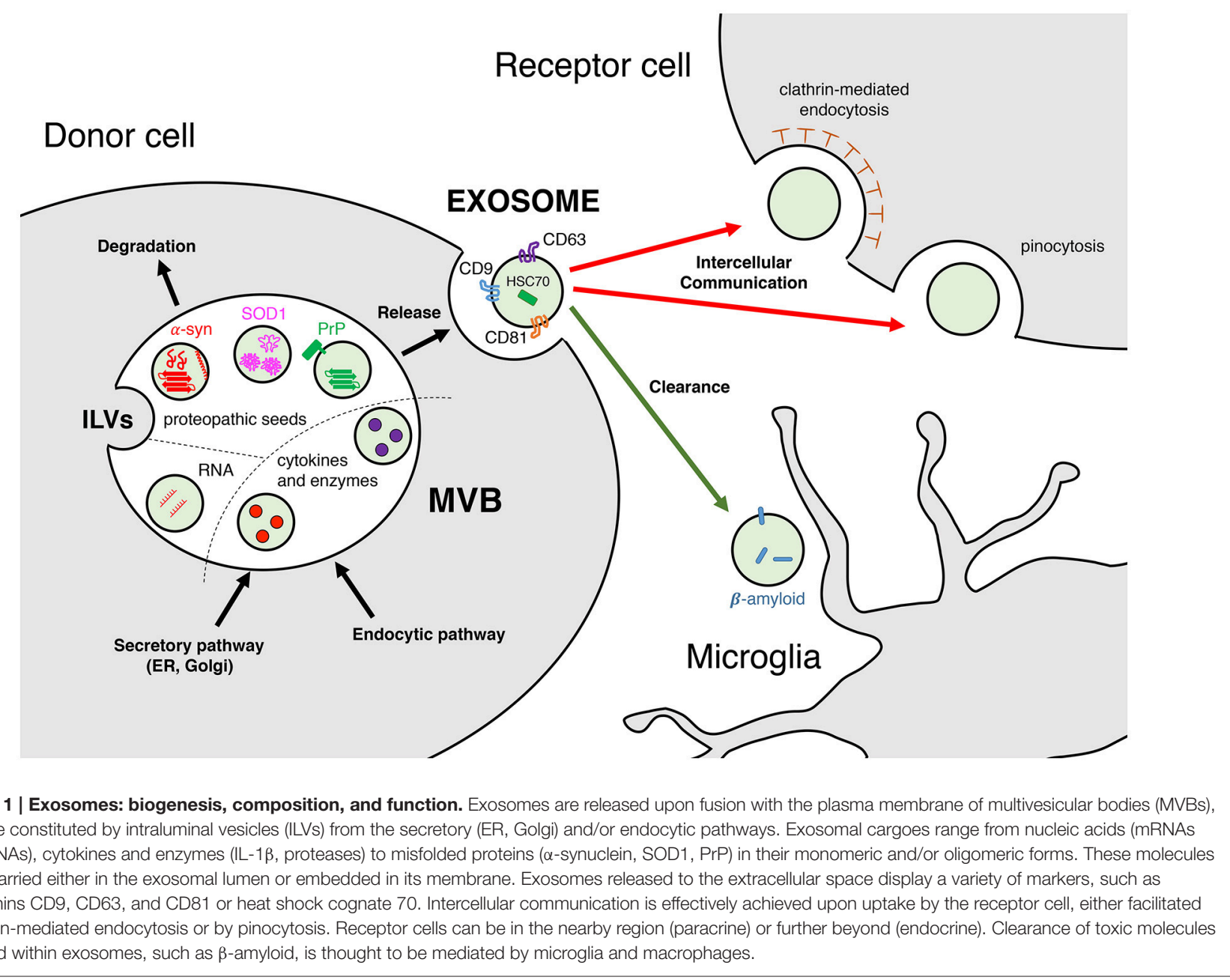

However, conflicting reports exist about the stabilization of $A \beta$ toxic species inside MVBs. Some authors suggest that exosomes promote aggregation of $\mathrm{A} \beta$, serving as nucleation hubs for plaque formation (Dinkins et al., 2014; Falker et al., 2016). This hypothesis would render exosomes as neuroprotective compartments, which clear toxic oligomeric species of $A \beta$ in favor of the more stable and less toxic fibrils. In contrast, others propose that exosomes can indeed induce the disassembly of stable species into neurotoxic oligomers (Yuyama et al., 2012; Joshi et al., 2014), depending on whether the exosomes are of neuronal or myeloid origin, based on the idea that different membrane lipid compositions might affect $\mathrm{A} \beta$ assemblies.

Hyperphosphorylated misfolded tau, the primary component of neurofibrillary tangles and a cytopathological hallmark of $\mathrm{AD}$, is associated to exosomes in the CSF of AD patients (Saman et al., 2012). Several in vitro studies where tau is overexpressed suggest that this microtubule-associated protein is secreted via exosomes (Chai et al., 2012; Simon et al., 2012), and transmitted trans-synaptically through the extracellular space (Lee et al., 2012; Liu et al., 2012), which proposes a mechanism for the progressive spreading of tauopathy in the brain of $\mathrm{AD}$ patients.
Indeed, inhibition of exosomal secretory pathways reduces the propagation of Tau in vitro and in vivo (Asai et al., 2015) in a viral-mediated expression model. On the contrary, secretion of endogenous tau is regulated by neuronal activity (Pooler et al., 2013; Wu et al., 2016), and this physiological process appears to be exosome-independent (Pooler et al., 2013). Additional work in more intact preparations that avoid the possible artifacts from tau overexpression, is necessary to shed light into this subject.

The relevance of exosomes in proteinopathies should not only be explored from the point of view of intercellular transmission of proteopathic seeds. Indeed, there is still debate in the field about whether the pathological trait is transmitted by the misfolded protein itself, the so-called "prion-like" selfpropagation, or other signals induce the aberrant folding in selectively vulnerable neurons (Walsh and Selkoe, 2016). Indeed, a recent study showed that misfolded seeds can be found all over the brain, still suggesting a propagation of proteopathic seeds, while only a subset of the brain will indeed display aggregation and neurodegeneration (Alibhai et al., 2016). Looking into the problem from the latter perspective, exosomes might be carriers of molecules such as nucleic acids or enzymes that could exert 
a pathophysiological modification in an endocrine manner. For instance, secretion of enzymes that degrade $A \beta$ are associated to exosomes (Bulloj et al., 2010; Tamboli et al., 2010), and miRNAs transported within neuron-derived exosomes can activate glial cell functions, such as activation of microglial phagocytosis for the clearance of neurodegenerating dendrites (Bahrini et al., 2015). Furthermore, microglial and neuronal exosomes have been proposed to participate in the disposal of $A \beta$ in the brain (Yuyama et al., 2012, 2015), a concept that becomes further relevant given that impaired $A \beta$ clearance is a characteristic of $\mathrm{AD}$ (Mawuenyega et al., 2010). Altogether, the current state-ofthe-art in the field shows that not only cell-to-cell transmission, but also exosome-mediated communication and clearance might be important players in $\mathrm{AD}$.

\section{Parkinson's Disease and Other Synucleinopathies}

Alpha-synuclein ( $\alpha$-syn) is a major component of Lewy bodies (Spillantini et al., 1997), the neuropathological hallmark of Parkinson's Disease (PD) and Dementia with Lewy bodies (DLB). $\alpha$-Syn is a pre-synaptic protein that exists in an equilibrium between monomeric and oligomeric states. Mutations and other disease-related factors affect the aggregation dynamics, favoring the balance toward fibrillization (Dehay et al., 2015). The neurodegenerative process observed in PD spreads through anatomically interconnected regions in the CNS (Braak et al., 2003), and the pathogenic trait of misfolded $\alpha$-syn is thought to propagate through a prion-like process (Olanow and Prusiner, 2009; Lee et al., 2010). Very recently, a team demonstrated that exosomal $\alpha$-syn species isolated from the CSF of PD and DLB patients is able to promote aggregation of $\alpha$-syn (Stuendl et al., 2016). However, whether exosomes play a role in $\alpha$-syn spreading is still a matter of debate.

Among all proteopathic seeds, most reports of secretion associated to exosomes and related vesicles belongs to the $\alpha$ syn field (Emmanouilidou et al., 2010; Alvarez-Erviti et al., 2011a; Danzer et al., 2012; Kong et al., 2014; Shi et al., 2014; Tsunemi et al., 2014). The first report that identified $\alpha$-syn showed that this is a protein present in synaptic vesicles. Due to its cellular function, a link to exosomes might be related to its intrinsic function within the exocytic machinery at the pre-synaptic terminal (Bendor et al., 2013). Despite the fact that the physiological role of $\alpha$-syn is not completely understood, it has been suggested that $\alpha$-syn is involved in synaptic vesicular processing (Vargas et al., 2014), where it binds to the membrane and undergoes conformational changes that facilitate the generation of the vesicle curvature (Varkey et al., 2010; Westphal and Chandra, 2013). It has also been reported that $\alpha$-syn prefers membranes with high curvature (Jensen et al., 2011), like the ones found in the $50-100 \mathrm{~nm}$ exosomes. It is worth to note that non-monomeric, i.e., aggregated $\alpha$-syn, is unable to perform this task, and it is not clear whether membrane association induces or prevents oligomerization (Bendor et al., 2013). In the first study that characterized the secretion of $\alpha$-syn by unconventional secretory pathways, Lee et al. (2005) already discussed that its compartmentalization into vesicles could promote the misfolding of $\alpha$-syn. A recent study demonstrated that exosomes accelerate $\alpha$-syn aggregation (Grey et al., 2015), and that the lipid composition of the vesicles is critical for this process. The mechanism by which $\alpha$-syn is incorporated into exosomes is still unknown, but given the vast number of genes linked to PD that have a role in endocytic and autophagy pathways such as PARK2, GBA, LRRK2, or ATP13A2 (GanOr et al., 2015), the rapid advancement of research in vesicle trafficking might give some clues in the next years.

In multiple system atrophy (MSA), oligodendrocytes forming $\alpha$-syn-containing aggregates named glial cytoplasmic inclusions (GCIs) accumulate $\alpha$-syn, which is accompanied by demyelination and extensive dopaminergic neuronal loss throughout the brain. Although transgenic MSA models overexpressing $\alpha$-syn under different oligodendrocyte-specific promoters have been studied for a decade (Fernagut and Tison, 2012), the link between oligodendroglial $\alpha$-syn aggregation and neuronal death remains elusive. Moreover, as $\alpha$-syn is a predominantly neuronal protein, it is also unknown if oligodendrocytes in a disease state can synthesize $\alpha$-syn de novo, or if $\alpha$-syn is readily transferred from neurons. In this regard, there are several reports indicating that oligodendrocytes and neurons communicate via exosomes, which supports the hypothesis of $\alpha$-syn transfer between these two cell types (Kramer-Albers et al., 2007; Bakhti et al., 2011). This exosomal communication between neurons and oligodendrocytes includes the transfer of genetic information by miRNAs (Fruhbeis et al., 2013), which in fact are altered in MSA (Ubhi et al., 2014; Schafferer et al., 2016). Therefore, a potential involvement of the exosomal secretory pathway in the pathogenesis of MSA should not be overlooked.

\section{Amyotrophic Lateral Sclerosis and Huntington's Disease}

Amyotrophic lateral sclerosis (ALS) is characterized by the misfolding of $\mathrm{Cu} / \mathrm{Zn}$ superoxide dismutase (SOD1) into aberrant conformations, which has been pinpointed as a central event in familiar and sporadic forms of the disease (Bosco et al., 2010). In vitro, neurons secrete exosomes loaded with mutant SOD1 to the extracellular space (Gomes et al., 2007), where these exosomes are able to transmit the pathogenic trait to other neurons, and propagate the misfolding of SOD1 (Grad et al., 2014). Furthermore, astrocytes also secrete SOD1-loaded exosomes that are selectively toxic for motor neurons (Basso et al., 2013), showing that exosome-mediated transfer of mutant SOD1 is pathogenic.

TDP-43 is a nuclear protein that mislocalizes to the cytoplasm, aggregates and forms inclusions in ALS and in fronto-temporal dementia (FTD). Dipeptide repeat proteins (DPRs) are produced by the unconventional translation of the C9orf72, the most common mutated gene in ALS and FTD as well. Recently, both molecules have been associated with exosomal release and transport (Nonaka et al., 2013; Ding et al., 2015; Westergard et al., 2016), further suggesting a link between exosome-mediated communication and the disease.

Exosomes can also propagate toxic molecules in an interspecies manner. An interesting work showed recently a cellto-cell propagation of mutant Huntingtin (mtHtt) in exosomes using 143 CAG repeats fibroblasts and SH-SY5Y neuroblastoma cells. Furthermore, injecting newborn wild-type mice with 
human exosomes carrying $\mathrm{mtHtt}$ triggered Huntington diseaselike (HD) symptoms and pathology in these animals (Jeon et al., 2016), this being the first report of human-to-mouse exosomemediated propagation of toxic molecules.

\section{Multiple Sclerosis and Inflammation}

Inflammation is a central player in most neurodegenerative diseases. Neuroinflammatory processes exert profound changes not only in the vicinity but beyond the local environment of cells. In addition to the propagation of toxic proteins, exosomes also carry important inflammatory modulators, such as mRNAs, miRNAs, and cytokines (Gupta and Pulliam, 2014). Microglia, the resident macrophages of the CNS, can shed exosomes loaded with pro-inflammatory molecules such as IL-1 $\beta$ (Bianco et al., 2005) and other cytokines. Their scavenging functions are also crucial in the clearance of toxic seeds such as $A \beta$ (Yuyama et al., 2012). Furthermore, endocrine signals from hematopoietic cells directed to the brain can be transported by exosomes, a phenomenon that is augmented in a context of inflammation (Ridder et al., 2014). It is interesting to note that extracellular vesicles can readily cross the blood brain barrier, adding a communication channel by which systemic inflammation can modulate physiological processes in the CNS.

Multiple sclerosis (MS) is a demyelinating disease characterized by the loss of oligodendrocytes, where inflammation plays a prominent role (Compston and Coles, 2008). Increased levels of circulating exosomes are present in the inflammation-driven disease model of MS, experimental autoimmune encephalomyelitis (EAE). In this model, proinflammatory cytokines promote exosome release by immune cells, which in turn carry more pro-inflammatory molecules, spreading inflammation. Animals where exosome-release activity had been hampered showed reduced inflammation and EAE symptoms (Verderio et al., 2012). Another component in the pathogenesis of EAE is glutamate excitotoxicity (Pitt et al., 2000), which is characterized by pathological accumulation of this neurotransmitter and amino acids, among other features. Glutamate can indeed trigger the release of exosomes by oligodendrocytes (Fruhbeis et al., 2013), cells whose homeostasis is known to be altered in demyelinating diseases (Matute et al., 2001). These oligodendrocyte-derived exosomes regulate axon myelination (Bakhti et al., 2011). Nevertheless, despite accumulating evidence suggesting a role of exosomes in inflammatory processes during pathology, whether these extracellular vesicles participate in the interplay between inflammation and excitotoxicity in demyelinating diseases remains unanswered.

\section{EXOSOMES AS THERAPEUTIC AND DIAGNOSTIC TOOLS}

\section{Potential of Exosomes As Carriers for Disease-Modifying Strategies}

Although the exact mechanism of exosomal entry into the brain is not fully understood, it should be noted that exosomes are able to cross the blood brain barrier (Record et al., 2011;
Tominaga et al., 2015), rendering them as ideal vehicles to delivery molecules into the brain (Figure 2). Exosomes are able to transfer mRNAs, microRNAs or proteins, and they are thought to be an exchange mechanism between cells (Valadi et al., 2007; Simpson et al., 2008), suggesting that these vesicles could be a new delivery machinery especially for RNA interference (RNAi; Valadi et al., 2007; Simons and Raposo, 2009). Indeed, RNAi-based technologies need vectors, since siRNAs can be degraded by extracellular endonucleases present in the serum, cells or extracellular space, and are also immunogenic (Whitehead et al., 2011; Kalani et al., 2014). Regarding delivery, exosomes harbor interesting advantages over other delivery systems such as liposomes, since they have a prolonged half-life and no immunogenicity (Kalani et al., 2014).

The pioneer work of Alvarez-Erviti and coworkers has shown that exosomes can be engineered to target specific tissues (Alvarez-Erviti et al., 2011b). They inserted brain- or muscle-specific peptides in one of the most abundant exosomal membrane proteins: the lysosomal-associated membrane protein 2b (LAMP-2B). In the brain, the proof-of-concept was obtained by using exosomes that contain siRNA for brain-specific knockdown of $B A C E 1$, encoding the beta-secretase 1 enzyme, in wild type mice (Alvarez-Erviti et al., 2011b). In a more recent study, the same strategy was successfully used to knockdown $\alpha$-syn in transgenic mouse brain (Cooper et al., 2014). Altogether, these results suggest that exosomes might be interesting vehicles for RNAi delivery. As exosomes are able to target most brain cell types, these results pave the way to applicability in other diseases associated to $\alpha$-syn accumulation, such as MSA.

microRNAs are highly abundant and largely studied in the biology of exosomes, in part due to their importance in the regulation of gene expression. Therefore, delivery of miRNAscontaining exosomes can constitute a precious therapeutic tool (Ohno et al., 2013). In this sense, MSCs release exosomes that contain overexpressed miRNA-133b, which was found to improve the recovery of ischemic (MCAO) rats, including neurite remodeling in the infarcted area (Xin et al., 2016). The authors used in vitro exosomes from MSCs along with overexpression of $\mathrm{miR}-133 \mathrm{~b}^{+}$, which increased the release of exosomes from oxygen and glucose-deprived astrocytes. These experiments resulted in increased neurite branching, which suggests that secondary astrocyte release may contribute to neuronal plasticity and recovery after stroke. It should be noted that whereas in vivo MSCs are in charge of miRNA-containing exosome release, Xin et al. used astrocytes for the in vitro studies, a different cell type where the role and function of miRNAs might be substantially different. Interestingly, five miRNAs from the exosome-released pool showed differential expression levels during traumatic brain injury (TBI), for which miR-21 showed the larger change (Harrison et al., 2016). The authors hypothesize that the increase in miR-21 is due to its release in neuronal exosomes close to the injury boundary, in which vicinity reactive microglia was found.

Engineered nucleic acids, such as hydrophobically modified small interfering RNAs (hsiRNAs) have been shown to load 


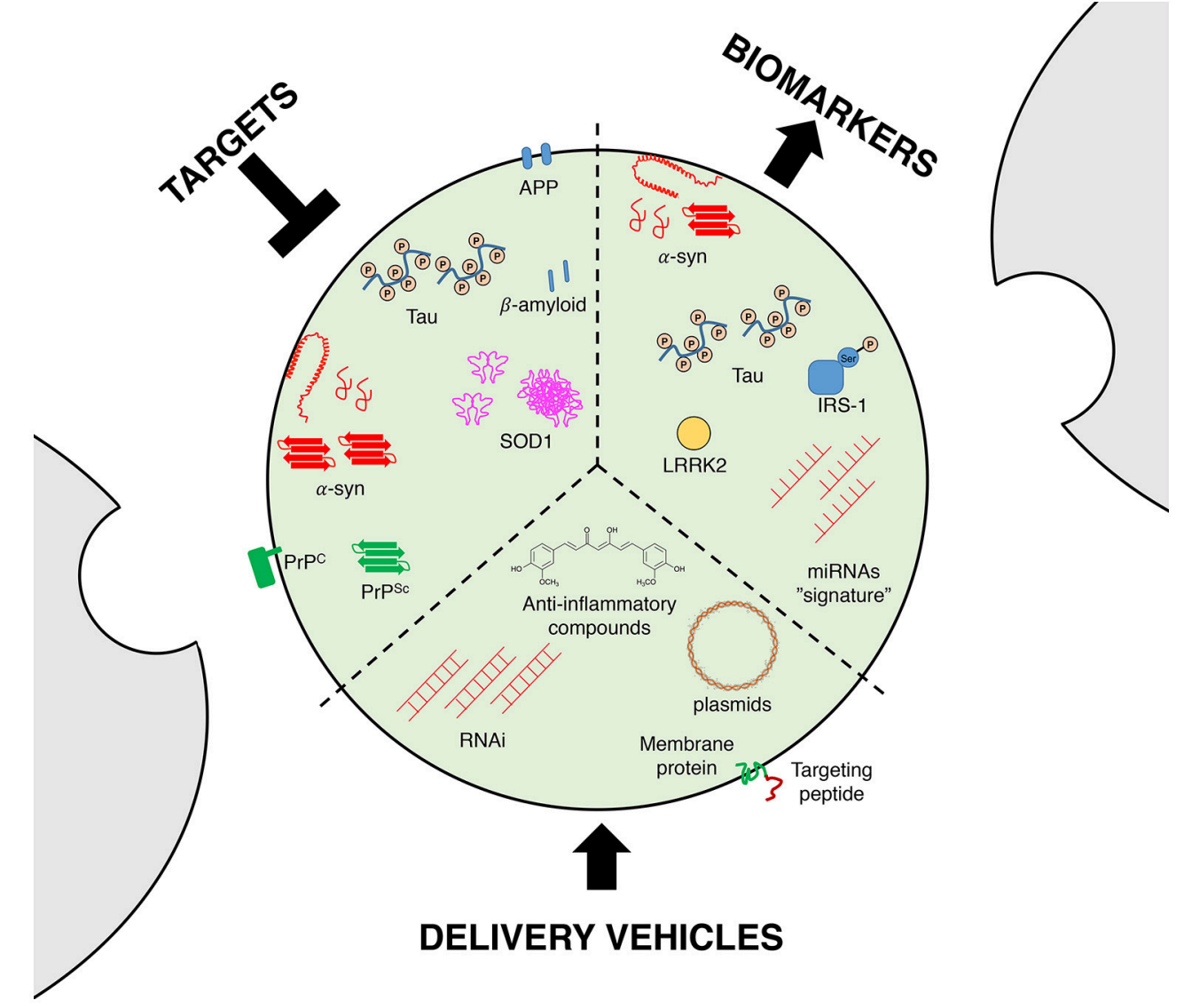

FIGURE 2 | Exosomes as therapeutic and diagnostic tools. Targeting the exosomal secretory pathway in neurodegenerative diseases has been proposed as a disease-modifying strategy, since it can reduce the propagation of proteopathic seeds and other toxic molecules. Exosomes can also serve as biomarkers, since they carry molecules relevant for diagnosis, such as disease-related proteins or unique sets of miRNAs (a proposed "signature" or "bar-code"). Finally, the resilience of exosomes in the extracellular milieu renders them as ideal vehicles for the delivery of drugs or disease-modifying molecules such as viral DNA or siRNAs, with the possibility of being targeted to specific cell types or tissues by genetic engineering of membrane proteins.

into exosomes (Didiot et al., 2016) and they constitute another example of the therapeutic potential of exosomes. In this work, hsiRNAs targeting Huntingtin (Htt) mRNA were efficiently internalized by primary cortical neurons in a dose-dependent manner, where they silenced up to $35 \%$ of Htt mRNA. Lastly, exosomes can also be carriers for neuron-specific rabies viral glycoprotein (RVG) peptide on the membrane, which delivers opioid receptor mu (MOR) siRNA into the brain associated with argonaute 2 (AGO2; Liu et al., 2015).

In addition to nucleic acids, exosomes have been successfully used to deliver drugs (Tian et al., 2014), and exosomes filled with anti-inflammatory compounds such as curcumin have been successfully administered to the brain through an intranasal route (Zhuang et al., 2011). In this experiment, microglia internalized exosomes within $60 \mathrm{~min}$ after delivery, and exosomedelivered curcumin successfully attenuated EAE symptoms. Although the distribution was mostly limited to olfactory bulbs, these results suggest that exosomes could be used broadly as molecule carriers for neurological disorders.

\section{Targeting Exosomes As a}

\section{Disease-Modifying Strategy Itself}

As mentioned earlier, exosomes are involved in the cell-to-cell transmission of neurodegenerative-related proteins. Indeed, several reports highlight that $\mathrm{PrP}$, tau or $\alpha$-syn can be released in exosomes (Lee et al., 2005; Aguzzi and Rajendran, 2009; Emmanouilidou et al., 2010; Saman et al., 2012). Taking into account the propagation of $\alpha$-syn as an example, the total amount of $\alpha$-syn in exosomes is low under basal conditions (Emmanouilidou et al., 2010). However, in pathological conditions exosomes could allow spreading between cells of pathological misfolded $\alpha$-syn. This "Trojan-horse" hypothesis leads to hypothesize that targeting exosome release might be a promising strategy to block disease propagation and progression (Figure 2). Future studies are still needed to unravel the relevance of such mechanism, as well as the molecular machinery underlying the import of neurodegenerative-related proteins into exosomes. Furthermore, targeting the exosomal secretory pathway without affecting its physiological communicational role might not be an easy task, and further work onto the basic 
physiological mechanisms of exosome release and cargo selection will be crucial in this matter.

\section{Exosomes As Biomarkers for Disease}

Since the identification of neurodegenerative disease related proteins in exosomes, these vesicles have been proposed as putative biomarkers to monitor disease progression (Figure 2). Exosomes can be isolated from multiple fluids including urine, blood or cerebrospinal fluid (CSF), which facilitates their clinical use as biomarkers (Street et al., 2012; Cheng et al., 2014a,b). Quantifications of neurodegenerative disease related proteins in total CSF or in exosomes purified from CSF have led to contradictory results in both AD and PD (Parnetti et al., 2013; Kim et al., 2016; Vella et al., 2016). Interestingly, a report has shown that hyperphosphorylated-tau (often considered as pathological tau) in exosomes is significantly increased in patients with mild forms of AD compared to controls (Saman et al., 2012). Although such result suggests that measuring tau phosphorylation in exosomes could be used as a biomarker for $\mathrm{AD}$, the fact that moderate or severe forms of the disease do not show similar phosphorylation levels dampens that hypothesis. One possible explanation could be that high levels of phosphorylated tau in exosomes is specific of a disease-stage, and not the entire pathological process. Regarding PD, similar divergences are also present in the literature. Indeed, a report showed that $\alpha$-syn is increased in microvesicles for PD patients while another did not observed variation in the $\alpha$-syn content (Shi et al., 2014; Tomlinson et al., 2015). This discrepancy could be explained by technical differences as well as differences in the patient population.

As many other proteins are present in exosomes, recent initiatives have used large-scale methodologies to analyze exosome content. Using mass-spectrometry to analyze circulating microvesicles, it was identified that PD patient fibroblasts are enriched in syntenin 1, a regulator of exosome biogenesis (Tomlinson et al., 2015). Similarly, a set of nine miRNAs have been shown to be distinct in exosomes purified from control and prion-infected cells (Bellingham et al., 2012a), defining a molecular "signature" that can identify a pathological process. Although the relevance of such hits in the disease is not established yet, these approaches suggest that establishing a "barcode" from the exosomal profile of patients might be a more valuable diagnostic tool than quantifying specific disease-related proteins, which are often mixed at early disease stages.

Exosomes can originate from most cell types and have been identified in most body fluids. A study identified the LeucineRich Repeat Kinase 2 (LRRK2), a protein involved in some hereditary forms of PD, in urinary exosomes (Fraser et al., 2013). The strong variability observed in clinical populations argued against its use as a biomarker for PD. However, one can hypothesize that exosomes originating from brain might be diluted in body fluids containing exosomes originating from other organs. To test this hypothesis, a recent study used an immunochemical method to purify brain exosomes from peripheral blood plasma (Shi et al., 2014). The authors reported an increase of $\alpha$-syn specifically in exosomes from plasma of PD patients (i.e., no overall modification was observed in total plasma). Although this approach was developed to be brainspecific based on the expression of the L1-cell adhesion molecule (L1-CAM), this protein is also expressed in the renal system (Allory et al., 2008; Vella et al., 2016), therefore these results have to be taken carefully. However, and more importantly, the immunochemical capture method provides an innovative approach for quantifying neurodegenerative disease related proteins in peripheral fluids to be used as biomarkers, and which hold the promise of a better specificity (Vella et al., 2016).

Interestingly, insulin resistance (i.e., decreased insulin/insulin like growth factor IGF-1 signaling) has been established in both MSA patients and in a well-characterized transgenic model, the PLP-SYN mice (Bassil et al., 2017). Insulin resistance can be measured by analyzing the amount of the downstream messenger insulin receptor substrate-1 phosphorylated at serine residues 312 (IRS-1pS312) or 616 (IRS-1pS616; Moloney et al., 2010; Talbot et al., 2012). Since this biomarker can be traced in peripheral exosomes (Kapogiannis et al., 2015), we evaluated the murine plasma neural derived exosomal IRS-1pS307 levels (corresponding to human IRS-1pS312) in transgenic MSA mice that were treated with the glucagon-like peptide-1 (GLP-1) agonist exenatide. We found a correlation with the number of nigral dopaminergic neurons and with striatal oligomeric $\alpha$-syn load in transgenic MSA mice, indicating that PLP-SYN mice with highest plasma exosomal IRS-1pS307 concentrations had a lower number of nigral TH and Nissl-stained neurons as well as higher striatal oligomeric $\alpha$-syn levels (Bassil et al., 2017). Altogether, these data suggest that peripheral neural derived exosomal IRS-1pS312 is an exosomal biomarker candidate that may serve as an objective outcome measure of target engagement for preclinical studies as well as clinical trials with GLP-1 analogs and other compounds modulating insulin/IGF-1 signaling.

\section{CONCLUDING REMARKS}

The last decade has witnessed a dramatic increase in publications in the field of exosomes and related extracellular vesicles. Initially considered waste disposal material, recent evidence has progressively changed this view, and exosomes are currently considered, in fact, as a broad intercellular communication system that can internalize, transport and transfer all types of biomolecules, from nucleic acids to peptides and proteins.

Most of the research in exosomes and extracellular vesicles has been carried out in cell cultures. This in vitro approach has been very useful to screen cell types, cargos, and genetic backgrounds, providing useful data to understand the biogenesis and physiological role of exosomes. However, their role in neurodegenerative diseases, either as carriers of diseasemodifying molecules, or as an effective clearance system, is yet to be completely understood. Several questions remain unanswered, mostly because of the lack of in vivo studies, as well as experiments in more intact preparations where the relevant molecules are expressed in endogenous levels. Among several open questions in the field, of particular interest, are (i) whether exosomes from diseased organisms can effectively propagate the pathogenic trait in vivo, (ii) whether targeting the exosomal 
secretory pathway can be beneficial for the pathology, and (iii) what is the molecular profile or "signature" that can be read from exosomes isolated from patients to be used as biomarkers in different brain disorders. Future studies will hopefully fulfill the high expectations raised among neurobiologists regarding the use of exosomes as therapeutic targets and/or tools.

\section{AUTHOR CONTRIBUTIONS}

FS, OP, MB, and $\mathrm{BD}$ were responsible for the conception of the article. FS, OP, MB, and BD did the scientific literature review. FS created the figures. FS, OP, MB, and BD wrote the first draft of the

\section{REFERENCES}

Abels, E. R., and Breakefield, X. O. (2016). Introduction to extracellular vesicles: biogenesis, RNA cargo selection, content, release, and uptake. Cell Mol. Neurobiol. 36, 301-312. doi: 10.1007/s10571-016-0366-z

Aguzzi, A., and Rajendran, L. (2009). The transcellular spread of cytosolic amyloids, prions, and prionoids. Neuron 64, 783-790. doi: 10.1016/j.neuron. 2009.12.016

Alibhai, J., Blanco, R. A., Barria, M. A., Piccardo, P., Caughey, B., Perry, V. H., et al. (2016). Distribution of misfolded prion protein seeding activity alone does not predict regions of neurodegeneration. PLoS Biol. 14:e1002579. doi: 10.1371/journal.pbio.1002579

Allory, Y., Audard, V., Fontanges, P., Ronco, P., and Debiec, H. (2008). The L1 cell adhesion molecule is a potential biomarker of human distal nephron injury in acute tubular necrosis. Kidney Int. 73, 751-758. doi: 10.1038/sj.ki.5002640

Alvarez-Erviti, L., Seow, Y., Schapira, A. H., Gardiner, C., Sargent, I. L., Wood, M. J., et al. (2011a). Lysosomal dysfunction increases exosome-mediated alpha-synuclein release and transmission. Neurobiol. Dis. 42, 360-367. doi: 10.1016/j.nbd.2011.01.029

Alvarez-Erviti, L., Seow, Y., Yin, H., Betts, C., Lakhal, S., and Wood, M. J. (2011b). Delivery of siRNA to the mouse brain by systemic injection of targeted exosomes. Nat. Biotechnol. 29, 341-345. doi: 10.1038/nbt.1807

Asai, H., Ikezu, S., Tsunoda, S., Medalla, M., Luebke, J., Haydar, T., et al. (2015). Depletion of microglia and inhibition of exosome synthesis halt tau propagation. Nat. Neurosci. 18, 1584-1593. doi: 10.1038/nn.4132

Atai, N. A., Balaj, L., Van Veen, H., Breakefield, X. O., Jarzyna, P. A., Van Noorden, C. J., et al. (2013). Heparin blocks transfer of extracellular vesicles between donor and recipient cells. J. Neurooncol. 115, 343-351. doi: 10.1007/s11060-013-1235-y

Bahrini, I., Song, J. H., Diez, D., and Hanayama, R. (2015). Neuronal exosomes facilitate synaptic pruning by up-regulating complement factors in microglia. Sci. Rep. 5:7989. doi: 10.1038/srep07989

Bakhti, M., Winter, C., and Simons, M. (2011). Inhibition of myelin membrane sheath formation by oligodendrocyte-derived exosome-like vesicles. J. Biol. Chem. 286, 787-796. doi: 10.1074/jbc.M110.190009

Bassil, F., Canron, M. H., Vital, A., Bezard, E., Li, Y., Greig, N. H., et al. (2017). Insulin resistance and exendin-4 treatment for multiple system atrophy. Brain.

Basso, M., Pozzi, S., Tortarolo, M., Fiordaliso, F., Bisighini, C., Pasetto, L., et al. (2013). Mutant copper-zinc superoxide dismutase (SOD1) induces protein secretion pathway alterations and exosome release in astrocytes: implications for disease spreading and motor neuron pathology in amyotrophic lateral sclerosis. J. Biol. Chem. 288, 15699-15711. doi: 10.1074/jbc.M112.425066

Bellingham, S. A., Coleman, B. M., and Hill, A. F. (2012a). Small RNA deep sequencing reveals a distinct miRNA signature released in exosomes from prion-infected neuronal cells. Nucleic Acids Res. 40, 10937-10949. doi: $10.1093 /$ nar/gks832

Bellingham, S. A., Guo, B. B., Coleman, B. M., and Hill, A. F. (2012b). Exosomes: vehicles for the transfer of toxic proteins associated with neurodegenerative diseases? Front. Physiol. 3:124. doi: 10.3389/fphys.2012. 00124 article. FS, OP, MB, WM, EB, and BD critically revised the entire manuscript and approved the final version.

\section{ACKNOWLEDGMENTS}

The University of Bordeaux and the Centre National de la Recherche Scientifique provided infrastructural support. This work was supported by Fondation de France (BD and EB), Fondation Simone and Cino Del Duca (EB), LABEX BRAIN ANR10-LABX-43 (EB), IdEx Université de Bordeaux (FS and $\mathrm{OP}$ ), and LECMA-Vaincre Alzheimer (OP). $\mathrm{MB}$ is recipient of France Parkinson and LABEX BRAIN fellowships.

Bendor, J. T., Logan, T. P., and Edwards, R. H. (2013). The function of alphasynuclein. Neuron 79, 1044-1066. doi: 10.1016/j.neuron.2013.09.004

Bianco, F., Pravettoni, E., Colombo, A., Schenk, U., Moller, T., Matteoli, M., et al. (2005). Astrocyte-derived ATP induces vesicle shedding and IL-1 beta release from microglia. J. Immunol. 174, 7268-7277. doi: 10.4049/jimmunol.174.11.7268

Bosco, D. A., Morfini, G., Karabacak, N. M., Song, Y., Gros-Louis, F., Pasinelli, P., et al. (2010). Wild-type and mutant SOD1 share an aberrant conformation and a common pathogenic pathway in ALS. Nat. Neurosci. 13, 1396-1403. doi: $10.1038 / \mathrm{nn} .2660$

Braak, H., Del Tredici, K., Rub, U., De Vos, R. A., Jansen Steur, E. N., and Braak, E. (2003). Staging of brain pathology related to sporadic Parkinson's disease. Neurobiol. Aging 24, 197-211. doi: 10.1016/S0197-4580(02)00065-9

Bulloj, A., Leal, M. C., Xu, H., Castano, E. M., and Morelli, L. (2010). Insulin-degrading enzyme sorting in exosomes: a secretory pathway for a key brain amyloid-beta degrading protease. J. Alzheimers. Dis. 19, 79-95. doi: 10.3233/JAD-2010-1206

Chai, X., Dage, J. L., and Citron, M. (2012). Constitutive secretion of tau protein by an unconventional mechanism. Neurobiol. Dis. 48, 356-366. doi: 10.1016/j.nbd.2012.05.021

Cheng, L., Sharples, R. A., Scicluna, B. J., and Hill, A. F. (2014a). Exosomes provide a protective and enriched source of miRNA for biomarker profiling compared to intracellular and cell-free blood. J. Extracell. Vesicles 3:23743. doi: $10.3402 /$ jev.v3.23743

Cheng, L., Sun, X., Scicluna, B. J., Coleman, B. M., and Hill, A. F. (2014b). Characterization and deep sequencing analysis of exosomal and non-exosomal miRNA in human urine. Kidney Int. 86, 433-444. doi: 10.1038/ki.2013.502

Christianson, H. C., Svensson, K. J., Van Kuppevelt, T. H., Li, J. P., and Belting, M. (2013). Cancer cell exosomes depend on cell-surface heparan sulfate proteoglycans for their internalization and functional activity. Proc. Natl. Acad. Sci. U.S.A. 110, 17380-17385. doi: 10.1073/pnas.1304266110

Coleman, B. M., Hanssen, E., Lawson, V. A., and Hill, A. F. (2012). Prion-infected cells regulate the release of exosomes with distinct ultrastructural features. FASEB J. 26, 4160-4173. doi: 10.1096/fj.11-202077

Collinge, J. (2001). Prion diseases of humans and animals: their causes and molecular basis. Annu. Rev. Neurosci. 24, 519-550. doi: 10.1146/annurev.neuro.24.1.519

Compston, A., and Coles, A. (2008). Multiple sclerosis. Lancet 372, 1502-1517. doi: 10.1016/S0140-6736(08)61620-7

Cooper, J. M., Wiklander, P. B., Nordin, J. Z., Al-Shawi, R., Wood, M. J., Vithlani, M., et al. (2014). Systemic exosomal siRNA delivery reduced alphasynuclein aggregates in brains of transgenic mice. Mov. Disord. 29, 1476-1485. doi: $10.1002 / \mathrm{mds} .25978$

Danzer, K. M., Kranich, L. R., Ruf, W. P., Cagsal-Getkin, O., Winslow, A. R., Zhu, L., et al. (2012). Exosomal cell-to-cell transmission of alpha synuclein oligomers. Mol. Neurodegener. 7:42. doi: 10.1186/1750-1326-7-42

Dehay, B., Bourdenx, M., Gorry, P., Przedborski, S., Vila, M., Hunot, S., et al. (2015). Targeting alpha-synuclein for treatment of Parkinson's disease: mechanistic and therapeutic considerations. Lancet Neurol. 14, 855-866. doi: 10.1016/S1474-4422(15)00006-X 
Didiot, M. C., Hall, L. M., Coles, A. H., Haraszti, R. A., Godinho, B. M., Chase, K., et al. (2016). Exosome-mediated delivery of hydrophobically modified siRNA for huntingtin mRNA silencing. Mol. Ther. 24, 1836-1847. doi: $10.1038 / \mathrm{mt} .2016 .126$

Ding, X., Ma, M., Teng, J., Teng, R. K., Zhou, S., Yin, J., et al. (2015). Exposure to ALS-FTD-CSF generates TDP-43 aggregates in glioblastoma cells through exosomes and TNTs-like structure. Oncotarget 6, 24178-24191. doi: 10.18632/oncotarget.4680

Dinkins, M. B., Dasgupta, S., Wang, G., Zhu, G., and Bieberich, E. (2014). Exosome reduction in vivo is associated with lower amyloid plaque load in the 5XFAD mouse model of Alzheimer's disease. Neurobiol. Aging 35, 1792-1800. doi: 10.1016/j.neurobiolaging.2014.02.012

Emmanouilidou, E., Melachroinou, K., Roumeliotis, T., Garbis, S. D., Ntzouni, M., Margaritis, L. H., et al. (2010). Cell-produced alpha-synuclein is secreted in a calcium-dependent manner by exosomes and impacts neuronal survival. J. Neurosci. 30, 6838-6851. doi: 10.1523/JNEUROSCI.5699-09.2010

Falker, C., Hartmann, A., Guett, I., Dohler, F., Altmeppen, H., Betzel, C., et al. (2016). Exosomal cellular prion protein drives fibrillization of amyloid beta and counteracts amyloid beta-mediated neurotoxicity. J. Neurochem. 137, 88-100. doi: 10.1111/jnc.13514

Feng, D., Zhao, W. L., Ye, Y. Y., Bai, X. C., Liu, R. Q., Chang, L. F., et al. (2010). Cellular internalization of exosomes occurs through phagocytosis. Traffic 11, 675-687. doi: 10.1111/j.1600-0854.2010.01041.x

Fernagut, P. O., and Tison, F. (2012). Animal models of multiple system atrophy. Neuroscience 211, 77-82. doi: 10.1016/j.neuroscience.2011.09.044

Fevrier, B., Vilette, D., Archer, F., Loew, D., Faigle, W., Vidal, M., et al. (2004). Cells release prions in association with exosomes. Proc. Natl. Acad. Sci. U.S.A. 101, 9683-9688. doi: 10.1073/pnas.0308413101

Fitzner, D., Schnaars, M., Van Rossum, D., Krishnamoorthy, G., Dibaj, P., Bakhti, M., et al. (2011). Selective transfer of exosomes from oligodendrocytes to microglia by macropinocytosis. J. Cell Sci. 124, 447-458. doi: $10.1242 /$ jcs.074088

Fraser, K. B., Moehle, M. S., Daher, J. P., Webber, P. J., Williams, J. Y., Stewart, C. A., et al. (2013). LRRK2 secretion in exosomes is regulated by 14-3-3. Hum. Mol. Genet. 22, 4988-5000. doi: 10.1093/hmg/ddt346

Fruhbeis, C., Frohlich, D., Kuo, W. P., Amphornrat, J., Thilemann, S., Saab, A. S., et al. (2013). Neurotransmitter-triggered transfer of exosomes mediates oligodendrocyte-neuron communication. PLoS Biol. 11:e1001604. doi: 10.1371/journal.pbio.1001604

Gabrielli, M., Battista, N., Riganti, L., Prada, I., Antonucci, F., Cantone, L., et al. (2015). Active endocannabinoids are secreted on extracellular membrane vesicles. EMBO Rep. 16, 213-220. doi: 10.15252/embr.201439668

Gan-Or, Z., Dion, P. A., and Rouleau, G. A. (2015). Genetic perspective on the role of the autophagy-lysosome pathway in Parkinson disease. Autophagy 11, 1443-1457. doi: 10.1080/15548627.2015.1067364

Gomes, C., Keller, S., Altevogt, P., and Costa, J. (2007). Evidence for secretion of $\mathrm{Cu}, \mathrm{Zn}$ superoxide dismutase via exosomes from a cell model of amyotrophic lateral sclerosis. Neurosci. Lett. 428, 43-46. doi: 10.1016/j.neulet.2007.09.024

Grad, L. I., Yerbury, J. J., Turner, B. J., Guest, W. C., Pokrishevsky, E., O'neill, M. A., et al. (2014). Intercellular propagated misfolding of wildtype $\mathrm{Cu} / \mathrm{Zn}$ superoxide dismutase occurs via exosome-dependent and independent mechanisms. Proc. Natl. Acad. Sci. U.S.A. 111, 3620-3625. doi: 10.1073/pnas.1312245111

Grey, M., Dunning, C. J., Gaspar, R., Grey, C., Brundin, P., Sparr, E., et al. (2015). Acceleration of alpha-synuclein aggregation by exosomes. J. Biol. Chem. 290, 2969-2982. doi: 10.1074/jbc.M114.585703

Guduric-Fuchs, J., O'connor, A., Camp, B., O'neill, C. L., Medina, R. J., and Simpson, D. A. (2012). Selective extracellular vesicle-mediated export of an overlapping set of microRNAs from multiple cell types. BMC Genomics 13:357. doi: 10.1186/1471-2164-13-357

Guo, B. B., Bellingham, S. A., and Hill, A. F. (2016). Stimulating the release of exosomes increases the intercellular transfer of prions. J. Biol. Chem. 291, 5128-5137. doi: 10.1074/jbc.M115.684258

Gupta, A., and Pulliam, L. (2014). Exosomes as mediators of neuroinflammation. J. Neuroinflam. 11:68. doi: 10.1186/1742-2094-11-68

Harrison, E. B., Hochfelder, C. G., Lamberty, B. G., Meays, B. M., Morsey, B. M., Kelso, M. L., et al. (2016). Traumatic brain injury increases levels of miR-21 in extracellular vesicles: implications for neuroinflammation. FEBS Open Bio. 6, 835-846. doi: 10.1002/2211-5463.12092

Jenjaroenpun, P., Kremenska, Y., Nair, V. M., Kremenskoy, M., Joseph, B., and Kurochkin, I. V. (2013). Characterization of RNA in exosomes secreted by human breast cancer cell lines using next-generation sequencing. PeerJ 1:e201. doi: 10.7717/peerj.201

Jensen, M. B., Bhatia, V. K., Jao, C. C., Rasmussen, J. E., Pedersen, S. L., Jensen, K. J., et al. (2011). Membrane curvature sensing by amphipathic helices: a single liposome study using alpha-synuclein and annexin B12. J. Biol. Chem. 286, 42603-42614. doi: 10.1074/jbc.M111.271130

Jeon, I., Cicchetti, F., Cisbani, G., Lee, S., Li, E., Bae, J., et al. (2016). Human-tomouse prion-like propagation of mutant huntingtin protein. Acta Neuropathol. 132, 577-592. doi: 10.1007/s00401-016-1582-9

Joshi, P., Turola, E., Ruiz, A., Bergami, A., Libera, D. D., Benussi, L., et al. (2014). Microglia convert aggregated amyloid-beta into neurotoxic forms through the shedding of microvesicles. Cell Death Differ. 21, 582-593. doi: $10.1038 / \mathrm{cdd} .2013 .180$

Jucker, M., and Walker, L. C. (2013). Self-propagation of pathogenic protein aggregates in neurodegenerative diseases. Nature 501, 45-51. doi: 10.1038/nature12481

Kalani, A., Tyagi, A., and Tyagi, N. (2014). Exosomes: mediators of neurodegeneration, neuroprotection and therapeutics. Mol. Neurobiol. 49, 590-600. doi: 10.1007/s12035-013-8544-1

Kalra, H., Simpson, R. J., Ji, H., Aikawa, E., Altevogt, P., Askenase, P., et al. (2012). Vesiclepedia: a compendium for extracellular vesicles with continuous community annotation. PLoS Biol. 10:e1001450. doi: 10.1371/journal.pbio.1001450

Kapogiannis, D., Boxer, A., Schwartz, J. B., Abner, E. L., Biragyn, A., Masharani, U., et al. (2015). Dysfunctionally phosphorylated type 1 insulin receptor substrate in neural-derived blood exosomes of preclinical Alzheimer's disease. FASEB J. 29, 589-596. doi: 10.1096/fj.14-262048

Kim, D.-K., Kang, B., Kim, O. Y., Choi, D.-s., Lee, J., Kim, S. R., et al. (2013). EVpedia: an integrated database of high-throughput data for systemic analyses of extracellular vesicles. J. Extracell. Vesicles 2:20384. doi: 10.3402/jev.v2i0.20384

Kim, D., Kim, Y. S., Shin, D. W., Park, C. S., and Kang, J. H. (2016). Harnessing cerebrospinal fluid biomarkers in clinical trials for treating Alzheimer's and Parkinson's diseases: potential and challenges. J. Clin. Neurol. 12, 381-392. doi: $10.3988 /$ jcn.2016.12.4.381

Kong, S. M., Chan, B. K., Park, J. S., Hill, K. J., Aitken, J. B., Cottle, L., et al. (2014). Parkinson's disease-linked human PARK9/ATP13A2 maintains zinc homeostasis and promotes alpha-Synuclein externalization via exosomes. Hum. Mol. Genet. 23, 2816-2833. doi: 10.1093/hmg/ddu099

Korkut, C., Ataman, B., Ramachandran, P., Ashley, J., Barria, R., Gherbesi, N., et al. (2009). Trans-synaptic transmission of vesicular Wnt signals through Evi/Wntless. Cell 139, 393-404. doi: 10.1016/j.cell.2009.07.051

Kramer-Albers, E. M., Bretz, N., Tenzer, S., Winterstein, C., Mobius, W., Berger, H., et al. (2007). Oligodendrocytes secrete exosomes containing major myelin and stress-protective proteins: trophic support for axons? Proteomics Clin. Appl. 1, 1446-1461. doi: 10.1002/prca.200700522

Lachenal, G., Pernet-Gallay, K., Chivet, M., Hemming, F. J., Belly, A., Bodon, G., et al. (2011). Release of exosomes from differentiated neurons and its regulation by synaptic glutamatergic activity. Mol. Cell. Neurosci. 46, 409-418. doi: 10.1016/j.mcn.2010.11.004

Lee, H. J., Patel, S., and Lee, S. J. (2005). Intravesicular localization and exocytosis of alpha-synuclein and its aggregates. J. Neurosci. 25, 6016-6024. doi: 10.1523/JNEUROSCI.0692-05.2005

Lee, S. J., Desplats, P., Sigurdson, C., Tsigelny, I., and Masliah, E. (2010). Cell-tocell transmission of non-prion protein aggregates. Nat. Rev. Neurol. 6, 702-706. doi: 10.1038/nrneurol.2010.145

Lee, S., Kim, W., Li, Z., and Hall, G. F. (2012). Accumulation of vesicleassociated human tau in distal dendrites drives degeneration and tau secretion in an in situ cellular tauopathy model. Int. J. Alzheimers. Dis. 2012, 172837. doi: 10.1155/2012/172837

Liu, L., Drouet, V., Wu, J. W., Witter, M. P., Small, S. A., Clelland, C., et al. (2012). Trans-synaptic spread of tau pathology in vivo. PLoS ONE 7:e31302. doi: 10.1371/journal.pone.0031302 
Liu, Y., Li, D., Liu, Z., Zhou, Y., Chu, D., Li, X., et al. (2015). Targeted exosomemediated delivery of opioid receptor Mu siRNA for the treatment of morphine relapse. Sci. Rep. 5:17543. doi: 10.1038/srep17543

Lopez-Verrilli, M. A., Caviedes, A., Cabrera, A., Sandoval, S., Wyneken, U., and Khoury, M. (2016). Mesenchymal stem cell-derived exosomes from different sources selectively promote neuritic outgrowth. Neuroscience 320, 129-139. doi: 10.1016/j.neuroscience.2016.01.061

Mathivanan, S., and Simpson, R. J. (2009). ExoCarta: a compendium of exosomal proteins and RNA. Proteomics 9, 4997-5000. doi: 10.1002/pmic.2009 00351

Mathivanan, S., Fahner, C. J., Reid, G. E., and Simpson, R. J. (2012). ExoCarta 2012: database of exosomal proteins, RNA and lipids. Nucleic Acids Res. 40, D1241-D1244. doi: 10.1093/nar/gkr828

Mathivanan, S., Ji, H., and Simpson, R. J. (2010). Exosomes: extracellular organelles important in intercellular communication. J. Proteomics 73, 1907-1920. doi: 10.1016/j.jprot.2010.06.006

Matute, C., Alberdi, E., Domercq, M., Perez-Cerda, F., Perez-Samartin, A., and Sanchez-Gomez, M. V. (2001). The link between excitotoxic oligodendroglial death and demyelinating diseases. Trends Neurosci. 24, 224-230. doi: 10.1016/S0166-2236(00)01746-X

Mawuenyega, K. G., Sigurdson, W., Ovod, V., Munsell, L., Kasten, T., Morris, J. C., et al. (2010). Decreased clearance of CNS beta-amyloid in Alzheimer's disease. Science 330, 1774. doi: 10.1126/science.1197623

Mittelbrunn, M., Vicente-Manzanares, M., and Sanchez-Madrid, F. (2015). Organizing polarized delivery of exosomes at synapses. Traffic 16, 327-337. doi: $10.1111 /$ tra. 12258

Moloney, A. M., Griffin, R. J., Timmons, S., O'connor, R., Ravid, R., and O'neill, C. (2010). Defects in IGF-1 receptor, insulin receptor and IRS-1/2 in Alzheimer's disease indicate possible resistance to IGF-1 and insulin signalling. Neurobiol. Aging 31, 224-243. doi: 10.1016/j.neurobiolaging.2008.04.002

Nonaka, T., Masuda-Suzukake, M., Arai, T., Hasegawa, Y., Akatsu, H., Obi, T., et al. (2013). Prion-like properties of pathological TDP-43 aggregates from diseased brains. Cell Rep. 4, 124-134. doi: 10.1016/j.celrep.2013.06.007

Ohno, S., Takanashi, M., Sudo, K., Ueda, S., Ishikawa, A., Matsuyama, N., et al. (2013). Systemically injected exosomes targeted to EGFR deliver antitumor microRNA to breast cancer cells. Mol. Ther. 21, 185-191. doi: $10.1038 / \mathrm{mt} .2012 .180$

Olanow, C. W., and Prusiner, S. B. (2009). Is Parkinson's disease a prion disorder? Proc. Natl. Acad. Sci. U.S.A. 106, 12571-12572. doi: 10.1073/pnas.0906759106

Parnetti, L., Castrioto, A., Chiasserini, D., Persichetti, E., Tambasco, N., El-Agnaf, O., et al. (2013). Cerebrospinal fluid biomarkers in Parkinson disease. Nat. Rev. Neurol. 9, 131-140. doi: 10.1038/nrneurol.2013.10

Perez-Gonzalez, R., Gauthier, S. A., Kumar, A., and Levy, E. (2012). The exosome secretory pathway transports amyloid precursor protein carboxyl-terminal fragments from the cell into the brain extracellular space. J. Biol. Chem. 287, 43108-43115. doi: 10.1074/jbc.M112.404467

Pitt, D., Werner, P., and Raine, C. S. (2000). Glutamate excitotoxicity in a model of multiple sclerosis. Nat. Med. 6, 67-70. doi: 10.1038/71555

Plebanek, M. P., Mutharasan, R. K., Volpert, O., Matov, A., Gatlin, J. C., and Thaxton, C. S. (2015). Nanoparticle targeting and cholesterol flux through scavenger receptor type B-1 inhibits cellular exosome uptake. Sci. Rep. 5:15724. doi: $10.1038 /$ srep 15724

Pooler, A. M., Phillips, E. C., Lau, D. H., Noble, W., and Hanger, D. P. (2013). Physiological release of endogenous tau is stimulated by neuronal activity. EMBO Rep. 14, 389-394. doi: 10.1038/embor.2013.15

Prusiner, S. B. (1982). Novel proteinaceous infectious particles cause scrapie. Science 216, 136-144. doi: 10.1126/science.6801762

Rajendran, L., Honsho, M., Zahn, T. R., Keller, P., Geiger, K. D., Verkade, P., et al. (2006). Alzheimer's disease beta-amyloid peptides are released in association with exosomes. Proc. Natl. Acad. Sci. U.S.A. 103, 11172-11177. doi: $10.1073 /$ pnas. 0603838103

Record, M., Subra, C., Silvente-Poirot, S., and Poirot, M. (2011). Exosomes as intercellular signalosomes and pharmacological effectors. Biochem. Pharmacol. 81, 1171-1182. doi: 10.1016/j.bcp.2011.02.011

Ridder, K., Keller, S., Dams, M., Rupp, A. K., Schlaudraff, J., Del Turco, D., et al. (2014). Extracellular vesicle-mediated transfer of genetic information between the hematopoietic system and the brain in response to inflammation. PLoS Biol. 12:e1001874. doi: 10.1371/journal.pbio.1001874
Saman, S., Kim, W., Raya, M., Visnick, Y., Miro, S., Saman, S., et al. (2012). Exosome-associated tau is secreted in tauopathy models and is selectively phosphorylated in cerebrospinal fluid in early Alzheimer disease. J. Biol. Chem. 287, 3842-3849. doi: 10.1074/jbc.M111.277061

Schafferer, S., Khurana, R., Refolo, V., Venezia, S., Sturm, E., Piatti, P., et al. (2016). Changes in the miRNA-mRNA regulatory network precede motor symptoms in a mouse model of multiple system atrophy: clinical implications. PLOS ONE 11:e0150705. doi: 10.1371/journal.pone.0150705

Schorey, J. S., and Bhatnagar, S. (2008). Exosome function: from tumor immunology to pathogen biology. Traffic 9, 871-881. doi: 10.1111/j.1600-0854. 2008.00734.x

Sharples, R. A., Vella, L. J., Nisbet, R. M., Naylor, R., Perez, K., Barnham, K. J., et al. (2008). Inhibition of gamma-secretase causes increased secretion of amyloid precursor protein C-terminal fragments in association with exosomes. FASEB J. 22, 1469-1478. doi: 10.1096/fj.07-9357com

Sheller, S., Papaconstantinou, J., Urrabaz-Garza, R., Richardson, L., Saade, G., Salomon, C., et al. (2016). Amnion-epithelial-cell-derived exosomes demonstrate physiologic state of cell under oxidative stress. PLOS ONE 11:e0157614. doi: 10.1371/journal.pone.0157614

Shi, M., Liu, C., Cook, T. J., Bullock, K. M., Zhao, Y., Ginghina, C., et al. (2014). Plasma exosomal alpha-synuclein is likely CNS-derived and increased in Parkinson's disease. Acta Neuropathol. 128, 639-650. doi: 10.1007/s00401-014-1314-y

Simon, D., Garcia-Garcia, E., Royo, F., Falcon-Perez, J. M., and Avila, J. (2012). Proteostasis of tau. Tau overexpression results in its secretion via membrane vesicles. FEBS Lett. 586, 47-54. doi: 10.1016/j.febslet.2011.11.022

Simons, M., and Raposo, G. (2009). Exosomes-vesicular carriers for intercellular communication. Curr. Opin. Cell Biol. 21, 575-581. doi: 10.1016/j.ceb.2009.03.007

Simpson, R. J., Jensen, S. S., and Lim, J. W. (2008). Proteomic profiling of exosomes: current perspectives. Proteomics 8, 4083-4099. doi: 10.1002/ pmic. 200800109

Simpson, R. J., Kalra, H., and Mathivanan, S. (2012). ExoCarta as a resource for exosomal research. J. Extracell. Vesicles 1:18374. doi: 10.3402/jev.v1i0.18374

Spillantini, M. G., Schmidt, M. L., Lee, V. M., Trojanowski, J. Q., Jakes, R., and Goedert, M. (1997). Alpha-synuclein in Lewy bodies. Nature 388, 839-840. doi: $10.1038 / 42166$

Street, J. M., Barran, P. E., Mackay, C. L., Weidt, S., Balmforth, C., Walsh, T. S., et al. (2012). Identification and proteomic profiling of exosomes in human cerebrospinal fluid. J. Transl. Med. 10:5. doi: 10.1186/14795876-10-5

Stuendl, A., Kunadt, M., Kruse, N., Bartels, C., Moebius, W., Danzer, K. M., et al. (2016). Induction of alpha-synuclein aggregate formation by CSF exosomes from patients with Parkinson's disease and dementia with Lewy bodies. Brain 139, 481-494. doi: 10.1093/brain/awv346

Subra, C., Laulagnier, K., Perret, B., and Record, M. (2007). Exosome lipidomics unravels lipid sorting at the level of multivesicular bodies. Biochimie 89, 205-212. doi: 10.1016/j.biochi.2006.10.014

Talbot, K., Wang, H. Y., Kazi, H., Han, L. Y., Bakshi, K. P., Stucky, A., et al. (2012). Demonstrated brain insulin resistance in Alzheimer's disease patients is associated with IGF-1 resistance, IRS-1 dysregulation, and cognitive decline. J. Clin. Invest. 122, 1316-1338. doi: 10.1172/JCI59903

Tamboli, I. Y., Barth, E., Christian, L., Siepmann, M., Kumar, S., Singh, S., et al. (2010). Statins promote the degradation of extracellular amyloid beta-peptide by microglia via stimulation of exosome-associated insulindegrading enzyme (IDE) secretion. J. Biol. Chem. 285, 37405-37414. doi: $10.1074 /$ jbc.M110.149468

Tian, Y., Li, S., Song, J., Ji, T., Zhu, M., Anderson, G. J., et al. (2014). A doxorubicin delivery platform using engineered natural membrane vesicle exosomes for targeted tumor therapy. Biomaterials 35, 2383-2390. doi: 10.1016/j.biomaterials.2013.11.083

Tominaga, N., Kosaka, N., Ono, M., Katsuda, T., Yoshioka, Y., Tamura, K., et al. (2015). Brain metastatic cancer cells release microRNA-181c-containing extracellular vesicles capable of destructing blood-brain barrier. Nat. Commun. 6, 6716. doi: 10.1038/ncomms7716

Tomlinson, P. R., Zheng, Y., Fischer, R., Heidasch, R., Gardiner, C., Evetts, S., et al. (2015). Identification of distinct circulating exosomes in Parkinson's disease. Ann. Clin. Transl. Neurol. 2, 353-361. doi: 10.1002/acn3.175 
Tsunemi, T., Hamada, K., and Krainc, D. (2014). ATP13A2/PARK9 regulates secretion of exosomes and alpha-synuclein. J. Neurosci. 34, 15281-15287. doi: 10.1523/JNEUROSCI.1629-14.2014

Ubhi, K., Rockenstein, E., Kragh, C., Inglis, C., Spencer, B., Michael, S., et al. (2014). Widespread microRNA dysregulation in multiple system atrophy - disease-related alteration in miR-96. Eur. J. Neurosci. 39, 1026-1041. doi: 10.1111/ejn.12444

Valadi, H., Ekstrom, K., Bossios, A., Sjostrand, M., Lee, J. J., and Lotvall, J. O. (2007). Exosome-mediated transfer of mRNAs and microRNAs is a novel mechanism of genetic exchange between cells. Nat. Cell Biol. 9, 654-659. doi: $10.1038 /$ ncb1596

Vargas, K. J., Makani, S., Davis, T., Westphal, C. H., Castillo, P. E., and Chandra, S. S. (2014). Synucleins regulate the kinetics of synaptic vesicle endocytosis. J. Neurosci. 34, 9364-9376. doi: 10.1523/JNEUROSCI.4787-13.2014

Varkey, J., Isas, J. M., Mizuno, N., Jensen, M. B., Bhatia, V. K., Jao, C. C., et al. (2010). Membrane curvature induction and tubulation are common features of synucleins and apolipoproteins. J. Biol. Chem. 285, 32486-32493. doi: 10.1074/jbc.M110.139576

Vella, L. J., Greenwood, D. L., Cappai, R., Scheerlinck, J. P., and Hill, A. F. (2008). Enrichment of prion protein in exosomes derived from ovine cerebral spinal fluid. Vet. Immunol. Immunopathol. 124, 385-393. doi: 10.1016/j.vetimm.2008.04.002

Vella, L. J., Hill, A. F., and Cheng, L. (2016). Focus on extracellular vesicles: exosomes and their role in protein trafficking and biomarker potential in Alzheimer's and Parkinson's disease. Int. J. Mol. Sci. 17:173. doi: 10.3390/ijms17020173

Vella, L. J., Sharples, R. A., Lawson, V. A., Masters, C. L., Cappai, R., and Hill, A. F. (2007). Packaging of prions into exosomes is associated with a novel pathway of PrP processing. J. Pathol. 211, 582-590. doi: 10.1002/path.2145

Verderio, C., Muzio, L., Turola, E., Bergami, A., Novellino, L., Ruffini, F., et al. (2012). Myeloid microvesicles are a marker and therapeutic target for neuroinflammation. Ann. Neurol. 72, 610-624. doi: 10.1002/ana.23627

Walsh, D. M., and Selkoe, D. J. (2016). A critical appraisal of the pathogenic protein spread hypothesis of neurodegeneration. Nat. Rev. Neurosci. 17, 251-260. doi: $10.1038 /$ nrn.2016.13

Westergard, T., Jensen, B. K., Wen, X., Cai, J., Kropf, E., Iacovitti, L., et al. (2016). Cell-to-cell transmission of dipeptide repeat proteins linked to C9orf72ALS/FTD. Cell Rep. 17, 645-652. doi: 10.1016/j.celrep.2016.09.032

Westphal, C. H., and Chandra, S. S. (2013). Monomeric synucleins generate membrane curvature. J. Biol. Chem. 288, 1829-1840. doi: 10.1074/jbc. M112.418871

Whitehead, K. A., Dahlman, J. E., Langer, R. S., and Anderson, D. G. (2011). Silencing or stimulation? siRNA delivery and the immune system. Annu. Rev. Chem. Biomol. Eng. 2, 77-96. doi: 10.1146/annurev-chembioeng061010-114133
Wu, J. W., Hussaini, S. A., Bastille, I. M., Rodriguez, G. A., Mrejeru, A., Rilett, K., et al. (2016). Neuronal activity enhances tau propagation and tau pathology in vivo. Nat. Neurosci. 19, 1085-1092. doi: 10.1038/nn.4328

Xin, H., Wang, F., Li, Y., Lu, Q.-E., Cheung, W. L., Zhang, Y., et al. (2016). Secondary release of exosomes from astrocytes contributes to the increase in neural plasticity and improvement of functional recovery after stroke in rats treated with exosomes harvested from microRNA 133boverexpressed multipotent mesenchymal stromal cells. Cell Transplant. doi: 10.3727/096368916X693031

Yagi, Y., Ohkubo, T., Kawaji, H., Machida, A., Miyata, H., Goda, S., et al. (2016). Next-generation sequencing-based small RNA profiling of cerebrospinal fluid exosomes. Neurosci. Lett. 636, 48-57. doi: 10.1016/j.neulet.2016.10.042

Yang, J. M., and Gould, S. J. (2013). The cis-acting signals that target proteins to exosomes and microvesicles. Biochem. Soc. Trans. 41, 277-282. doi: 10.1042/BST20120275

Yim, Y. I., Park, B. C., Yadavalli, R., Zhao, X., Eisenberg, E., and Greene, L. E. (2015). The multivesicular body is the major internal site of prion conversion. J. Cell Sci. 128, 1434-1443. doi: 10.1242/jcs.165472

Yuyama, K., Sun, H., Mitsutake, S., and Igarashi, Y. (2012). Sphingolipidmodulated exosome secretion promotes clearance of amyloid-beta by microglia. J. Biol. Chem. 287, 10977-10989. doi: 10.1074/jbc.M111.3 24616

Yuyama, K., Sun, H., Usuki, S., Sakai, S., Hanamatsu, H., Mioka, T., et al. (2015). A potential function for neuronal exosomes: sequestering intracerebral amyloid-beta peptide. FEBS Lett. 589, 84-88. doi: 10.1016/j.febslet.2014. 11.027

Zappulli, V., Friis, K. P., Fitzpatrick, Z., Maguire, C. A., and Breakefield, X. O. (2016). Extracellular vesicles and intercellular communication within the nervous system. J. Clin. Invest. 126, 1198-1207. doi: 10.1172/JCI81134

Zhuang, X., Xiang, X., Grizzle, W., Sun, D., Zhang, S., Axtell, R. C., et al. (2011). Treatment of brain inflammatory diseases by delivering exosome encapsulated anti-inflammatory drugs from the nasal region to the brain. Mol. Ther. 19 1769-1779. doi: 10.1038/mt.2011.164

Conflict of Interest Statement: The authors declare that the research was conducted in the absence of any commercial or financial relationships that could be construed as a potential conflict of interest.

Copyright (c) 2017 Soria, Pampliega, Bourdenx, Meissner, Bezard and Dehay. This is an open-access article distributed under the terms of the Creative Commons Attribution License (CC BY). The use, distribution or reproduction in other forums is permitted, provided the original author(s) or licensor are credited and that the original publication in this journal is cited, in accordance with accepted academic practice. No use, distribution or reproduction is permitted which does not comply with these terms. 